\title{
Studies of the Properties of Heat Treated Rolled Medium Carbon Steel
}

\author{
Daramola O. Oluyemi*, Oladele Isiaka Oluwole ${ }^{\mathrm{b}}$, B. O. Adewuyi ${ }^{\mathrm{b}}$ \\ ${ }^{\mathrm{a}}$ Ajaokuta Steel Rolling Mill Complex, Nigeria \\ ${ }^{\mathrm{b}}$ Metallurgical and Materials Engineering Department, \\ Federal University of Technology, Akure, Nigeria
}

Received: May 24, 2010; Revised: May 11, 2011

\begin{abstract}
Investigations were carried out to study critically the effects of heat treatment on the properties of rolled medium carbon steel. Representative samples of as-rolled medium carbon steel were subjected to heat treatment processes which are; Quenching, Lamellae Formation and Tempering in the following order $(Q+Q+L+T)$, $(\mathrm{Q}+\mathrm{L}+\mathrm{T})$ and $(\mathrm{L}+\mathrm{T})$. The steel was heated to the austenizing temperature of $830^{\circ} \mathrm{C}$ and water quenched. The quenched steel was subjected to lamellae formation by reheating it to the ferrite-austenite dual-phase region at a temperature of $745^{\circ} \mathrm{C}$ below the effective $\mathrm{A}_{\mathrm{C} 3}$ point and then rapidly quenched in water. The lamellae formed was tempered at $480{ }^{\circ} \mathrm{C}$ to provide an alloy containing strong, tough and lath martensite in a soft and ductile ferrite matrix. Mechanical tests were carried out on the samples and the results shows that the steel developed has excellent combination of tensile strength, hardness and impact strength which is very good for structural applications. The corrosion behaviour of the samples; heat treated rolled medium carbon steel and as-rolled medium carbon steel in sodium chloride medium were also investigated from where it was also confirmed that improved corrosion resistance is achievable by the treatment.
\end{abstract}

Keywords: heat treatment, mechanical properties, corrosion, medium carbon steel

\section{Introduction}

One reason for the versatility of metallic materials lies in the wide range of mechanical properties they possess, which are accessible to management by various means. Steel is an alloy of iron and carbon. Steel with low carbon content has the same properties as iron, soft but easily formed. As carbon content increases, the metal becomes harder and stronger but less ductile and more difficult to weld. Higher carbon content lowers steel melting point and its temperature resistance in general ${ }^{1}$. Medium carbon steel is steel with 0.3 to $0.7 \% \mathrm{C}$ and approximately $0.8 \% \mathrm{Mn}$ which are used in the production of machinery parts such as nuts and bolts, shafts and gears ${ }^{2}$.

Rolled medium carbon steel products are produced through a forming process called rolling. The process is carried out in a rolling mill which consists of a complex machine for deforming metal in rotary rolls followed by auxiliary operations such as cutting, cooling, piling or coiling. Before rolling, billets are charged into a reheating furnace with the aid of charging devices, the roller tables takes the billet to the reheating furnace one at a time where the billets are preheated and latter discharged and made to pass through the working group of stands where reduction is effected during rolling operations.

The desire to produce higher strength steels in the formability greater than those obtained in conventional controlled rolled high strength micro-alloyed grade has led to the development of microstructural strengthened steels ${ }^{3}$. Heat treatment involves the application of heat to a material in order to bring about changes in the microstructure and, hence, modify the material properties. During the heat treatment process, the material usually undergoes phase microstructural and crystallographic changes. The development of microstructure in both single-and two-phase alloys ordinarily involves some type of phase transformation-an alteration in the number and/ or character of the phases. These transformations can be divided into three classifications as: simple diffusion-dependent transformations in which there is no change in either the number or composition of the phases present; diffusion-dependent transformation where there is some alteration in phase compositions and often in the number of phases present, the final microstructure ordinarily consists of two phases and finally, diffusionless transformation where in a metastable phase is produced. Martensitic transformation which may be induced in some steel alloys falls into this category ${ }^{4}$. The purpose of heat treating carbon steel is to change the mechanical properties of steel, usually ductility, hardness, yield strength tensile strength and impact resistance. The impact strength of the heat-treated specimens are higher than that of the as rolled; This is as a result of the lath martensite alloy formed during the heat treatment processes which is very strong ${ }^{5}$. The electrical, corrosion and thermal conductivity are also slightly altered during heat treatment process. The standard strengths of steels used in the structural design are prescribed from their yield strength. Most engineering calculations for structure are based on yield strength.

When medium-carbon and medium-alloyed steels are annealed between the $\mathrm{A}_{\mathrm{Cl}}$ and $\mathrm{A}_{\mathrm{C} 3}$ and then water quenched, due to partial transformation taking place, a dual phase structure, i.e., a mixture embedded martensite islands within the grains of ferrite is usually obtained $^{6,7}$. A uniform microstructure with appropriate volume ratio, geometry and aspect ratio of martensite islands are often assigned suitable for mechanical properties assessments ${ }^{8}$. Dual phase steels are preferred in the automotive industry due to their low density and high load bearing capacity ${ }^{9}$. There have been many investigations on the microstructural development and mechanical properties of dual phase steels. It has generally been found that rather than the size, the volume fraction of the martensite islands is very effective on tensile properties ${ }^{10}$. Increasing the amount of martensite reduces the percent elongation considerably. Dual phase steels mostly have low 
yield strength, but on the contrary have high strain hardening rates during deformation ${ }^{11}$. It is not possible to find any study focusing on the effects of initial ferrite, pearlite and martensite grain sizes on microstructure and mostly on toughness of the material. It has been verified that microstructure particularly after an intermediate quenching treatment is different from that after an intercritical quenching process ${ }^{12}$. Thus, formation of fine martensite after intermediate quenching mostly degrades the tensile properties, but the percent elongation of the material increases gradually. This has been attributed to an increase in the density of mobile dislocations in the ferrite, while the mean grain size and the interparticle distance between the fine martensite islands becomes smaller ${ }^{13}$. This research work was carried out to determine the effect of heat treatment processes on locally rolled medium carbon steel and evaluate the effect of the heat treatment processes on the mechanical properties at the dual-phase region as well as the effect of corrosive media on the steel.

\section{Materials and Methods}

\subsection{Materials}

The material used in this study was $12 \mathrm{~mm}$ diameter rolled medium carbon steel bars. Samples of the material were collected and prepared into tensile, impact, hardness, corrosion and metallographic examination specimens. The spectrometric analysis of the steel was carried out to determine its chemical composition. The result is shown in Table 1.

\subsection{Methods}

\subsubsection{Determination of operating temperatures}

The lower critical temperature $\left(\mathrm{A}_{\mathrm{Cl}}\right)$ and upper critical temperature $\left(\mathrm{A}_{\mathrm{C} 3}\right)$ were determined by Grange empirical formula ${ }^{14}$ as presented below;

$$
\begin{aligned}
& \mathrm{A}_{\mathrm{C} 1}\left({ }^{\circ} \mathrm{C}\right)=(133-25 \mathrm{Mn}+40 \mathrm{Si}+42 \mathrm{Cr}-26 \mathrm{Ni})-(32) 5 / 9 \\
& \mathrm{~A}_{\mathrm{C} 3}\left({ }^{\circ} \mathrm{C}\right)=(1570-323 \mathrm{C}-25 \mathrm{Mn}+80 \mathrm{Si}-3 \mathrm{Cr}-32 \mathrm{Ni})-(32) 5 / 9
\end{aligned}
$$

The carbon equivalent and estimate of austenite carbon in equilibrium are calculated from the chemical composition as given by Mamora ${ }^{15}$ and Adewuyi ${ }^{16}$ and the values are shown in Table 2.

$$
C e q=\% C+\frac{\% M n}{6}+\frac{(C r+M o+V)}{5}+\frac{\%(N i+C u)}{15}
$$

\subsubsection{Heat treatment processes}

From Table 2, it was observed that medium carbon steel only exist within $\mathrm{Co}\left(735^{\circ} \mathrm{C}\right)$ and $\mathrm{Co}\left(745^{\circ} \mathrm{C}\right)$ and, this was used as the lamellae formation temperatures. Representative samples of as-rolled medium carbon steel were subjected to three sets of different heat treatment processes in the following order;

1. Quenching + Quenching + Lamellae Formation + Tempering $(\mathrm{Q}+\mathrm{Q}+\mathrm{L}+\mathrm{T})$.
The steel specimens were heated to the austenizing temperature of $830^{\circ} \mathrm{C}$, soaked for 20 minutes and quenched in water; this process was repeated again before the specimens were thereafter subjected to lamellae formation by heating them to the dual-phase region at a temperature of $735^{\circ} \mathrm{C}$, soaked for 20 minutes and quenched in water. The specimens were finally tempered at a temperature of $480{ }^{\circ} \mathrm{C}$ for 30 minutes. This was used as sample $\mathrm{A}_{1}$. The same process was also repeated where lamellae formation was carried out at $745^{\circ} \mathrm{C}$, soaked for 20 minutes and quenched in water which was used as sample $\mathrm{A}_{2}$.

2. Quenching + Lamellae Formation + Tempering $(\mathrm{Q}+\mathrm{L}+\mathrm{T})$

The steel specimens were heated to the austenizing temperature of $830^{\circ} \mathrm{C}$, soaked for 20 minutes and quenched in water; the specimens were subjected to lamellae formation by heating them to the dualphase region at a temperature of $735{ }^{\circ} \mathrm{C}$, soaked for 20 minutes and quenched in water. The specimens were finally tempered at a temperature of $480{ }^{\circ} \mathrm{C}$ for 30 minutes. This was used as sample $\mathrm{B}_{1}$. The same process was also repeated where lamellae formation was carried out at $745^{\circ} \mathrm{C}$, soaked for 20 minutes and quenched in water which was used as sample $\mathrm{B}_{2}$.

\section{Lamellae Formation + Tempering $(\mathrm{L}+\mathrm{T})$}

The specimens were subjected to lamellae formation by heating them to the dual-phase region at a temperature of $735{ }^{\circ} \mathrm{C}$, soaked for 20 minutes and quenched in water. The specimens were finally tempered at a temperature of $480{ }^{\circ} \mathrm{C}$ for 30 minutes. This was used as sample $\mathrm{C}_{1}$. The same process was also repeated where lamellae formation was carried out at $745^{\circ} \mathrm{C}$, soaked for 20 minutes and quenched in water which was used as sample $\mathrm{C}_{2}$.

\section{Mechanical Testing of Specimens}

\subsection{Tensile test}

Tensile test was carried out on the heat-treated and as-rolled medium carbon steel using Tensometer. The initial gauge length and diameter were measured before and after subjecting them to the test. The yield and maximum loads were recorded directly from the resulted graph. The readings that were obtained was used in the determination of the yield strength $\left(\sigma_{y}\right)$, ultimate tensile strength $\left(\sigma_{\mathrm{u}}\right)$, percentage elongation (\%E) and Yield Ratio (YR).

\subsection{Impact test}

Representative samples of as-rolled and heat-treated specimens were subjected to impact test on an Izod V-Notch impact testing machine. The pendulum of the machine is allowed to swing freely through a known angle while energy was introduced to break the specimen. The energy was recorded directly on the scale attached to the machine.

\subsection{Hardness test}

The hardness of as-rolled and heat-treated specimens were measured with the aid of Rockwell hardness tester Indentec 2007 model. This machine measures the resistance to penetration by measuring the depth of impression and the hardness is indicated

\begin{tabular}{|c|c|c|c|c|c|c|c|c|c|}
\hline $\mathrm{C}$ & $\mathrm{Si}$ & $\mathrm{Mn}$ & $\mathrm{P}$ & $\mathrm{S}$ & $\mathrm{Cr}$ & Mo & $\mathrm{Ni}$ & $\mathrm{Al}$ & $\mathrm{Co}$ \\
\hline 0.353 & 0.290 & 0.987 & 0.050 & 0.057 & 0.071 & 0.0050 & 0.110 & 0.025 & 0.015 \\
\hline $\mathrm{Cu}$ & $\mathrm{Nb}$ & $\mathrm{Ti}$ & $\mathrm{V}$ & $\mathrm{W}$ & $\mathrm{Pb}$ & $\mathrm{Sn}$ & $\mathrm{Zn}$ & $\mathrm{Fe}$ & \\
\hline 0.185 & 0.0050 & 0.0037 & 0.0057 & 0.010 & 0.0050 & 0.026 & 0.0076 & 97.805 & \\
\hline
\end{tabular}
directly on the scale attached to the machine.

Table 1. Chemical composition of as-rolled medium carbon steel in wt. (\%). 


\subsection{Corrosion test}

The corrosion rates of as-rolled specimen and heat treated specimens were measured by immersing these specimens in a solution of sodium chloride $(\mathrm{NaCl})$. The cross-sectional area of each of the specimens was calculated; each of the specimens was also weighed on a chemical balance and the weight recorded. The PH and the electrode potential of the corrosive medium were measured and recorded. After every 3 days interval ( 72 hours); specimens were retrieved, washed properly in water, dried and weighed on a weighing balance to determine the weight loss during exposure. The laboratory simulation experiments were carried out using $0.5 \mathrm{M} \mathrm{NaCl}$ medium.

Finally, the corrosion rate was calculated using

$$
m p y=\frac{3.45 \times 106 \mathrm{~W}}{D A T}
$$

where, $\mathrm{W}=$ weight loss in $\mathrm{g} ; \mathrm{D}=$ density of specimen in $\mathrm{g} \cdot \mathrm{cm}^{-3}$; $\mathrm{A}=$ Area in $\mathrm{cm}^{2} ; \mathrm{T}=$ Exposure Time in hour.

Table 2. Carbon equivalent (Ceq) and estimate of austenite carbon in equilibrium $(\mathrm{Co})$.

\begin{tabular}{cccc}
\hline Ceq & $\operatorname{Co}\left(735^{\circ} \mathrm{C}\right)$ & $\mathrm{Co}\left(745^{\circ} \mathrm{C}\right)$ & $\mathrm{Co}\left(840^{\circ} \mathrm{C}\right)$ \\
\hline 0.55 & 0.790 & 0.82 & 1.05 \\
\hline
\end{tabular}

\subsection{Microstructural examination}

Samples of as-rolled and heat-treated specimens were mounted on hot phenolic powder and ground with hand grinding set-up of abrasive papers (240, 320, 400 and 600 grades) that progress from coarsest to finest grit sizes using water as lubricant. Polishing was carried out on a rotating disc of a synthetic velvet polishing cloth impregnated with micron alumna paste. Final polishing was carried out with diamond paste. The specimens were then etched with the standard $2 \%$ natal so as to reveal the ferrite grain boundaries. The optical microscopic examinations were carried out on a metallurgical microscope at a magnification of 400X. The specimens were illuminated with $100 \mathrm{~kW}$ detachable quartz iodine lamp.

\section{Results and Discussion}

The tensile, hardness and impact energy results of the steel after various heat treatment processes are shown in Table 3 and Figures 1-6 while the result of the corrosion test was shown in Figures 7-12.

\subsection{Mechanical properties}

Figures 1 and 2 present the stress-strain curve of the heat treated specimens and as-rolled steel. From the results in Table 3, it was observed that, the ultimate tensile strength $\left(\sigma_{u}\right)$ and the percentage elongation of the steel developed by the heat treatment processes are

Table 3. Tensile, hardness and impact properties of as-rolled medium carbon steel and heat treated specimens.

\begin{tabular}{cccccccccc}
\hline $\begin{array}{c}\text { Heat } \\
\text { treatment } \\
\text { process }\end{array}$ & $\begin{array}{c}\text { Lamelarizing } \\
\text { temp. } \\
\left({ }^{\circ} \mathrm{C}\right)\end{array}$ & $\begin{array}{c}\text { Test } \\
\text { specimen } \\
\text { designation }\end{array}$ & $\begin{array}{c}\text { \%Reduction } \\
\text { in area } \\
(\%)\end{array}$ & $\begin{array}{c}\text { Yield } \\
\text { strength } \\
(\mathrm{MPa})\end{array}$ & $\begin{array}{c}\text { Ultimate } \\
\text { tensile } \\
\text { strength } \\
(\mathrm{MPa})\end{array}$ & $\begin{array}{c}\text { Yield ratio } \\
(\%)\end{array}$ & $\begin{array}{c}\% \\
\text { elongation }\end{array}$ & $\begin{array}{c}\text { Rockwell } \\
\text { hardness } \\
(\mathrm{HRA})\end{array}$ & $\begin{array}{c}\text { Impact } \\
\text { energy } \\
(\text { Joules })\end{array}$ \\
\hline \multirow{2}{*}{$\mathrm{Q}+\mathrm{Q}+\mathrm{L}+\mathrm{T}$} & 735 & $\mathrm{~A}_{1}$ & 67 & 478 & 603 & 79 & 22 & 61.30 & 58.70 \\
& 745 & $\mathrm{~A}_{2}$ & 72 & 489 & 618 & 79 & 22 & 61.50 & 57.90 \\
\hline \multirow{2}{*}{$\mathrm{Q}+\mathrm{L}+\mathrm{T}$} & 735 & $\mathrm{~B}_{1}$ & 75 & 401 & 569 & 71 & 27 & 56.70 & 60.30 \\
& 745 & $\mathrm{~B}_{2}$ & 66 & 484 & 614 & 79 & 25 & 59.70 & 58.60 \\
\hline \multirow{2}{*}{$\mathrm{L}+\mathrm{T}$} & 735 & $\mathrm{C}_{1}$ & 65 & 404 & 529 & 76 & 26 & 58.50 & 57.60 \\
\hline \multirow{2}{*}{ As-Rolled } & 745 & $\mathrm{C}_{2}$ & 61 & 444 & 607 & 73 & 24 & 58.70 & 56.70 \\
\hline
\end{tabular}

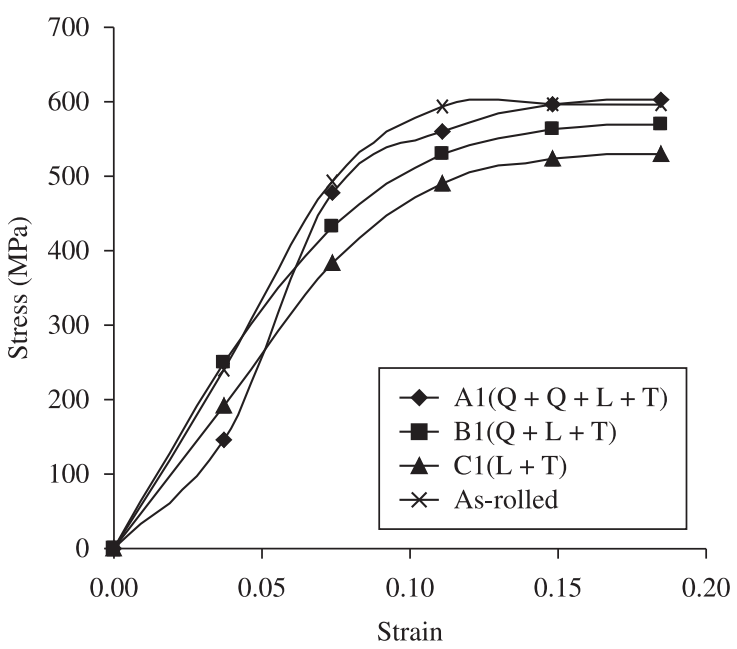

Figure 1. Stress strain curves of as-rolled steel and heat treated specimens $\left(\mathrm{A}_{1}, \mathrm{~B}_{1}, \mathrm{C}_{1}\right)$.

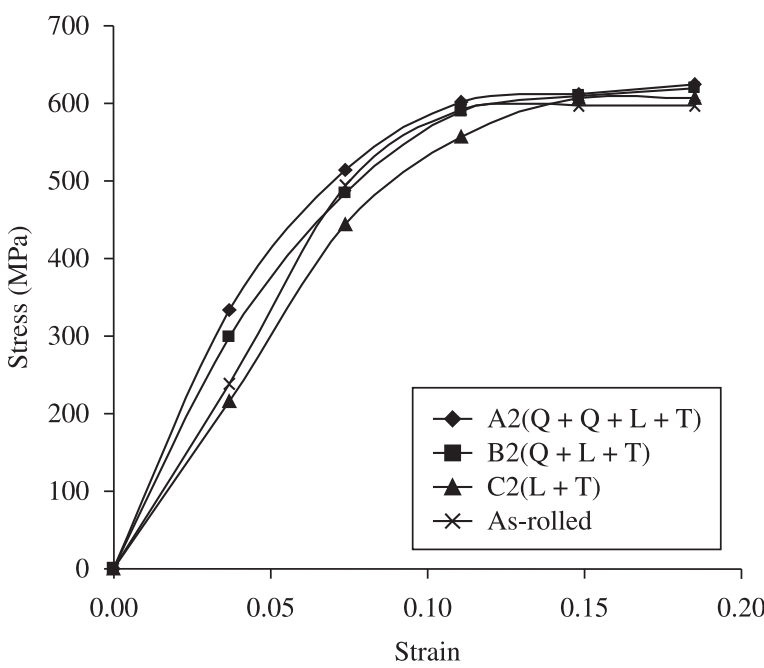

Figure 2. Stress strain curves of as-rolled steel and heat treated specimens $\left(\mathrm{A}_{2}, \mathrm{~B}_{2}, \mathrm{C}_{2}\right)$. 


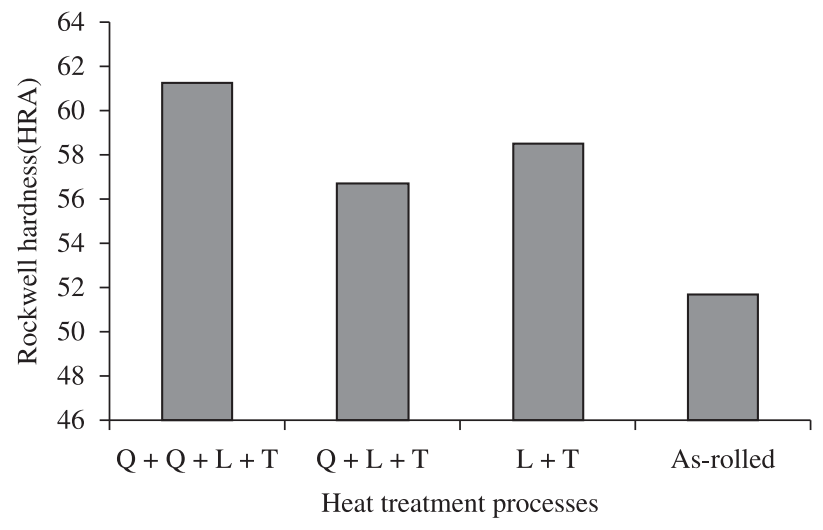

Figure 3. Rockwell hardness of as-rolled steel and heat treated specimens $\left(\mathrm{A}_{1}, \mathrm{~B}_{1}, \mathrm{C}_{1}\right)$.

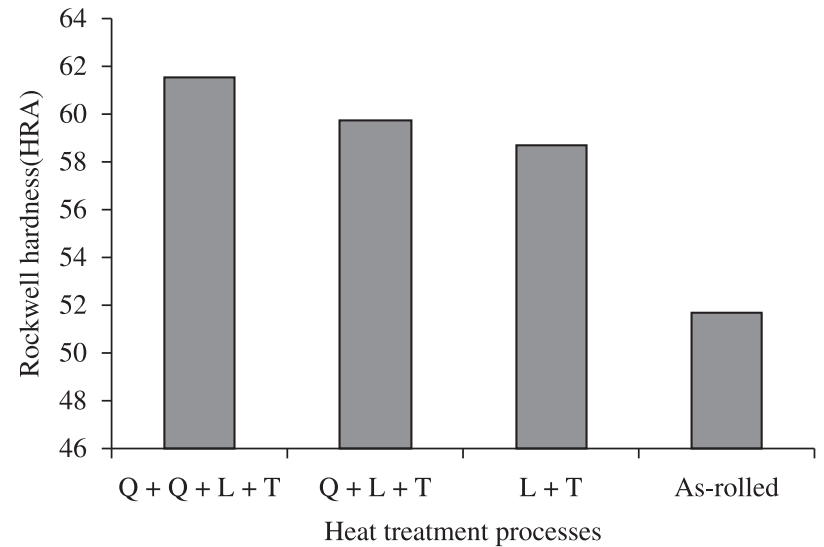

Figure 4. Rockwell hardness of as-rolled steel and heat treated specimens $\left(\mathrm{A}_{2}, \mathrm{~B}_{2}, \mathrm{C}_{2}\right)$.

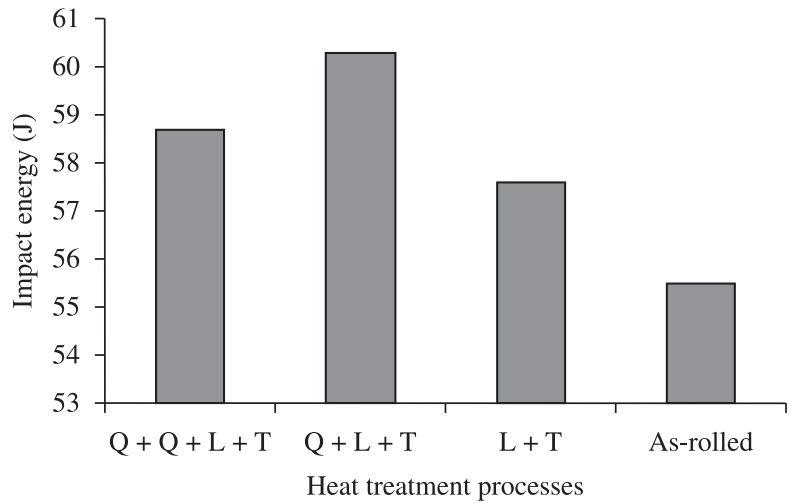

Figure 5. Impact strength of as-rolled steel and heat treated specimens $\left(\mathrm{A}_{1}, \mathrm{~B}_{1}, \mathrm{C}_{1}\right)$.

higher than that of the as-rolled steel. The results show that sample $\mathrm{A}_{2}$ with UTS of $618 \mathrm{MPa}$ followed by sample $\mathrm{B}_{2}$ with UTS of $614 \mathrm{MPa}$ and sample $\mathrm{C}_{2}$ with UTS of $607 \mathrm{MPa}$ has the best ultimate tensile strengths respectively. It was observed that the yield strength of as-rolled steel is higher than that of the heat treated processes in the following order; the as-rolled has $494 \mathrm{MPa}$ followed by sample $\mathrm{A}_{2}$ of $\mathrm{MPa}$, sample $\mathrm{B}_{2}$ of $484 \mathrm{MPa}$ and sample $\mathrm{A}_{1}$ of $478 \mathrm{MPa}$ respectively. The result shows that lamellae formation at $745{ }^{\circ} \mathrm{C}$ gives the best tensile properties. This was as a result of the strong deformable second phase structure formed during the heat treatment processes

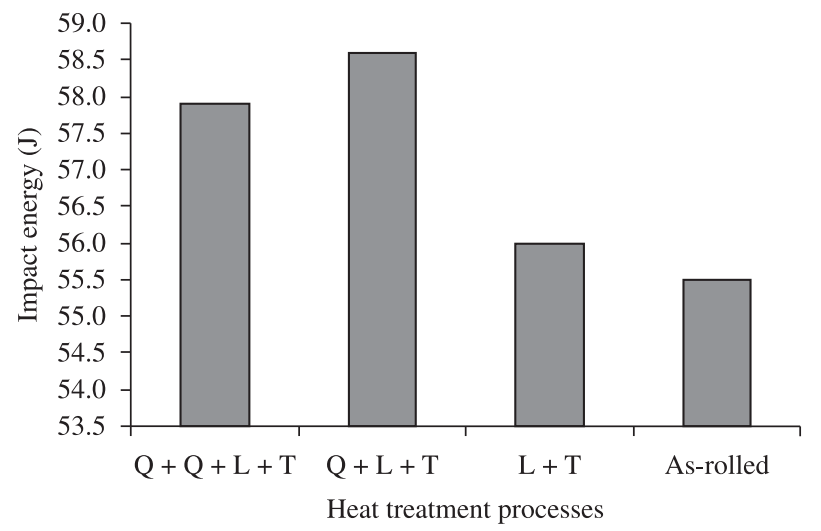

Figure 6. Impact strength of as-rolled steel and heat treated specimens $\left(\mathrm{A}_{2}, \mathrm{~B}_{2}, \mathrm{C}_{2}\right)$.

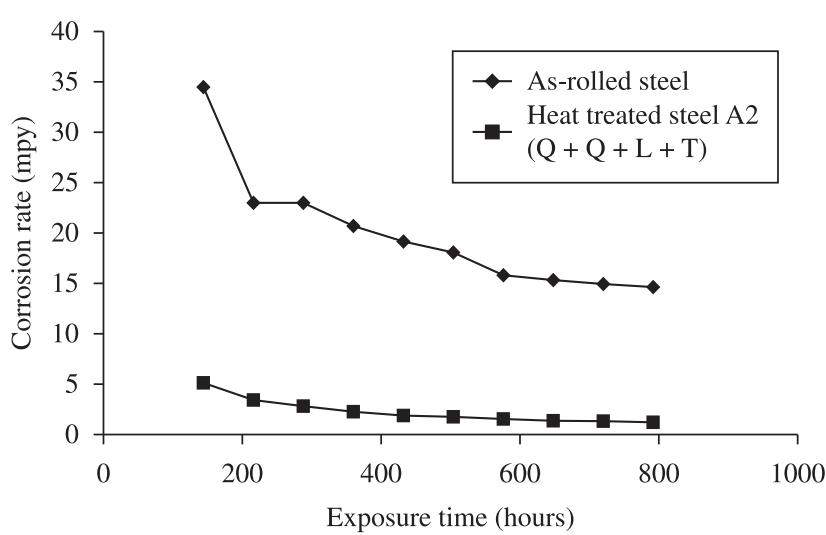

Figure 7. Corrosion rate of heat-treated specimen $A_{2}(Q+Q+L+T)$ and as-rolled steel in $0.5 \mathrm{M} \mathrm{NaCl}$ environment.

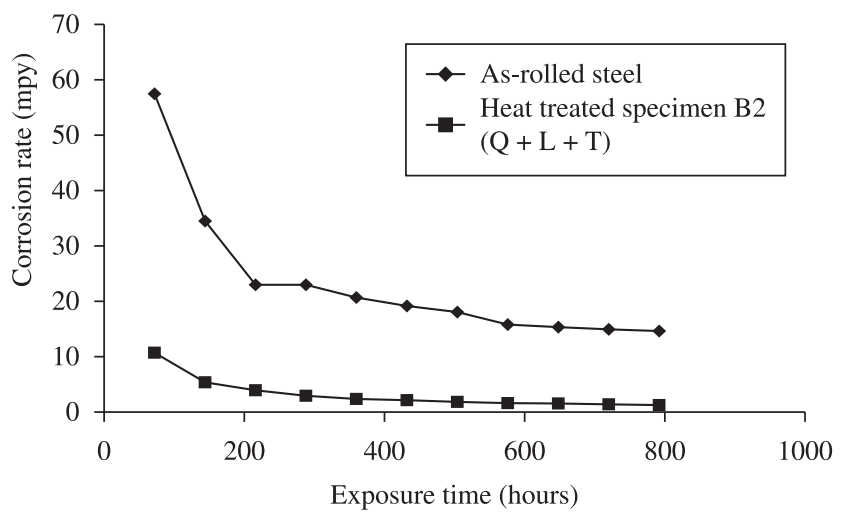

Figure 8. Corrosion rate of heat-treated specimen $\mathrm{B}_{2}(\mathrm{Q}+\mathrm{L}+\mathrm{T})$ and as-rolled steel in $0.5 \mathrm{M} \mathrm{NaCl}$ environment.

which consist of martensite. The strong second phase is dispersed in a soft ductile ferrite matrix. The martensite provides the strength in the steel whereas the ferrite provides the ductility. The increase in ductility and the tensile strength leads to better formability and makes the steel very attractive for use in cold-formed high strength components.

Figures 3 and 4 present the changes in the hardness values of the specimens. The Rockwell hardness values of the heat treated steels are higher than that of the as-rolled steel. From the results, it was observed that, sample $\mathrm{A}_{2}$ has the best value of $61.50 \mathrm{HRA}$ followed 


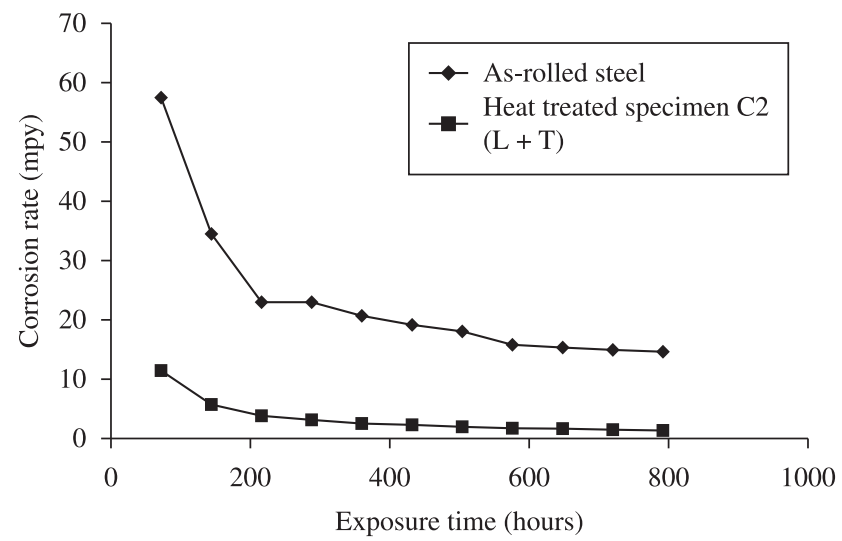

Figure 9. Corrosion rate of heat-treated specimen $\mathrm{C}_{2}(\mathrm{~L}+\mathrm{T})$ and as-rolled steel in $0.5 \mathrm{M} \mathrm{NaCl}$ environment.

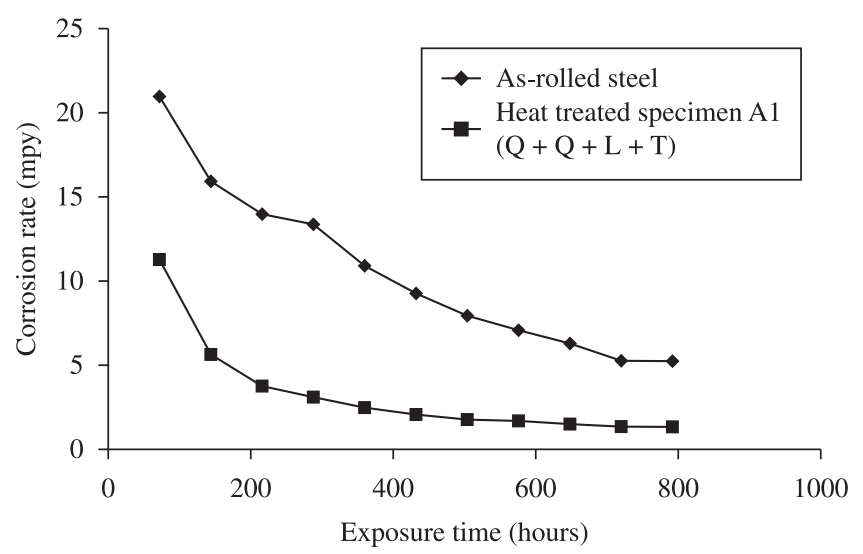

Figure 10. Corrosion rate of heat-treated specimen $A_{1}(Q+Q+L+T)$ and as-rolled steel in $0.5 \mathrm{M} \mathrm{NaCl}$ environment.

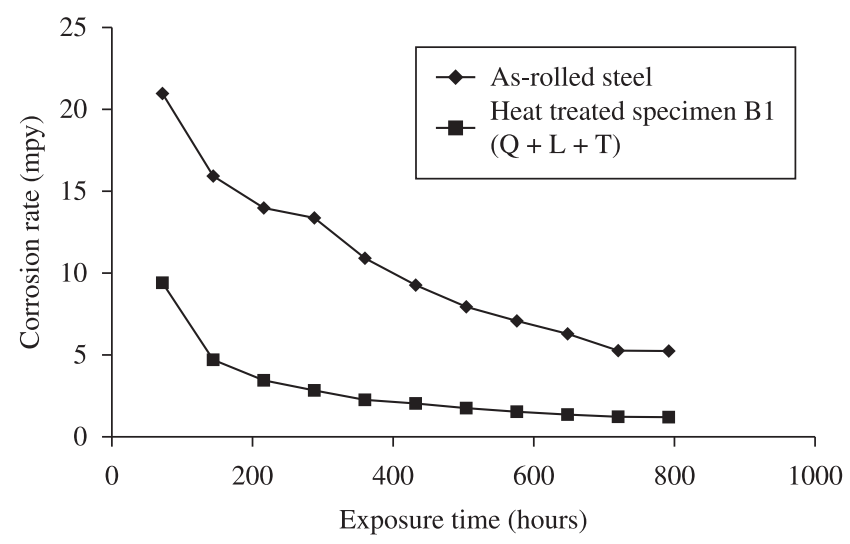

Figure 11. Corrosion rate of heat-treated specimen $B_{1}(Q+L+T)$ and asrolled steel in $0.5 \mathrm{M} \mathrm{NaCl}$ environment.

by sample $A_{1}$ with a value of $61.30 \mathrm{HRA}$ and sample $\mathrm{B}_{2}$ with a value of 59.70 HRA which was closely followed by sample $C_{2}$ with a value of 58.70 HRA.This was probably due to the higher volume fraction of the harder martensite in the developed steel. The transformation of austenite to martensite by a diffusionless shear type transformation in quenching is also responsible for higher hardness obtained and this property is attributed to the effectiveness of the interstitial carbon in hindering the dislocation motion ${ }^{17}$.

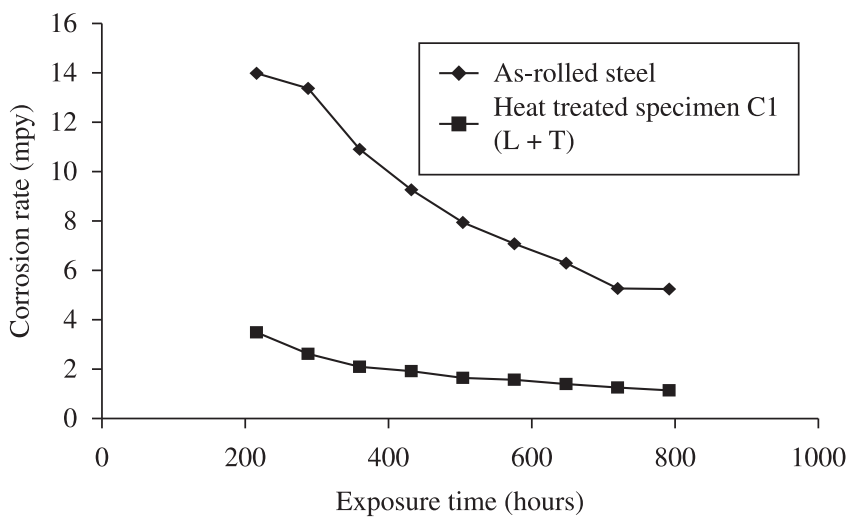

Figure 12. Corrosion rate of heat-treated specimen $C_{1}(L+T)$ and as-rolled steel in $0.5 \mathrm{M} \mathrm{NaCl}$ environment.

Figures 5 and 6 present the impact energy of the heat treated specimens and as-rolled medium carbon steel. The impact strength of the heat-treated specimens is higher than that of the as-rolled. The result showed that sample $B_{1}$ has the highest value of $60.30 \mathrm{~J}$ followed by sample $A_{1}$ with a value of $58.70 \mathrm{~J}$ and sample $B_{2}$ with a value of $58.60 \mathrm{~J}$ which was closely followed by sample $\mathrm{A}_{2}$ with a value of $57.90 \mathrm{~J}$. This is as a result of the lath martensite alloy formed during the heat treatment processes which is very strong and tough ${ }^{5}$.

\subsection{Corrosion properties}

The results of the corrosion rate of the heat treated specimens and as-rolled specimen is shown in Figures 7-12. The corrosion rates of the heat treated specimens in marine medium $(\mathrm{NaCl})$ is low when compared to the as-rolled steel, as shown in Figures 7-12. This is because the as-rolled steel consist mainly pearlitic-ferritic structure in which each crystal consist of alternate layers of ferrite and cementite. It was observed that ferrite is anodic to cementite and this corrode with moisture as the electrolyte ${ }^{18}$. This was confirmed from the microstructure of the as-rolled steel shown in Plates 1-7.

In the $\mathrm{NaCl}$ environment, the corrosion rate of the as-rolled steel was very high within the first 2 days and after this, the corrosion decreases with increase in exposure time; this is because the $\mathrm{FeCl}_{2}$ formed during the process is insoluble and forms a protective film on the corroding surface of the steel which effectively prevent corrosive medium from coming into contact with the steel and greatly reduces the corrosion rate[8]. After 20 days of exposure, the corrosion rate becomes uniform, this is because the steel is in the thermodynamically stable phase, the surface of the steel becomes immuned and no corrosion occurs as shown in Figures 8-12. It was observed that, the same trend of corrosion rate takes place for all the specimens. However, the steel developed by $\mathrm{Q}+\mathrm{L}+\mathrm{T}$ process have the least corrosion rate followed by $\mathrm{L}+\mathrm{T}$ process and $\mathrm{Q}+\mathrm{Q}+\mathrm{L}+\mathrm{T}$ process.

\subsection{Microstructures}

The microstructures obtained are shown in Figures 13a-d. The microstructure produced by the as-rolled steel consists of pearliticferritic structure while the microstructures produced by the processes consist of a duplex ferrite martensite microstructure. The strong deformable second phase consists predominantly martensite with some bainite and retained austenite. Martensite provides the strength in the steel whereas the ferrite provides the ductility. The strong second phase is dispersed in a soft ductile ferrite matrix. From the $\mathrm{L}+\mathrm{T}$ and $\mathrm{Q}+\mathrm{L}+\mathrm{T}$ processes, it was observed that, the ferrite volume fraction was high resulting in lower yield strength. Also, the 


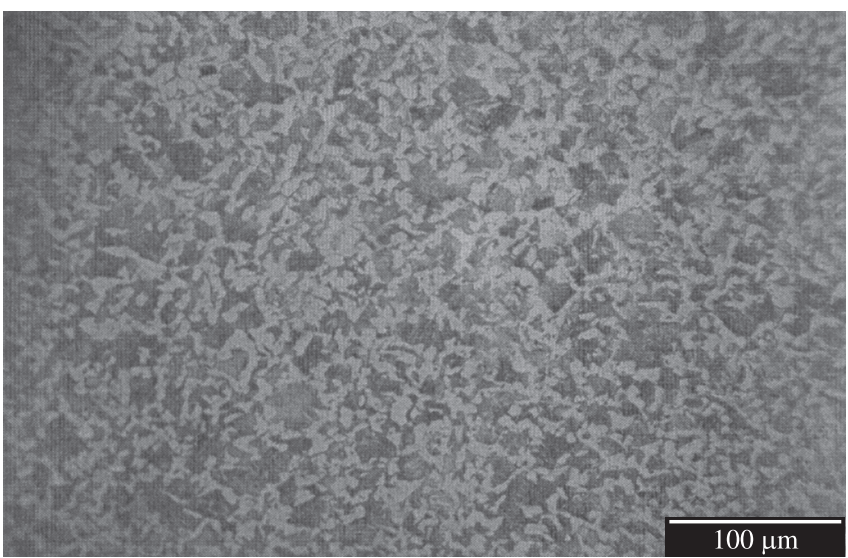

(a)

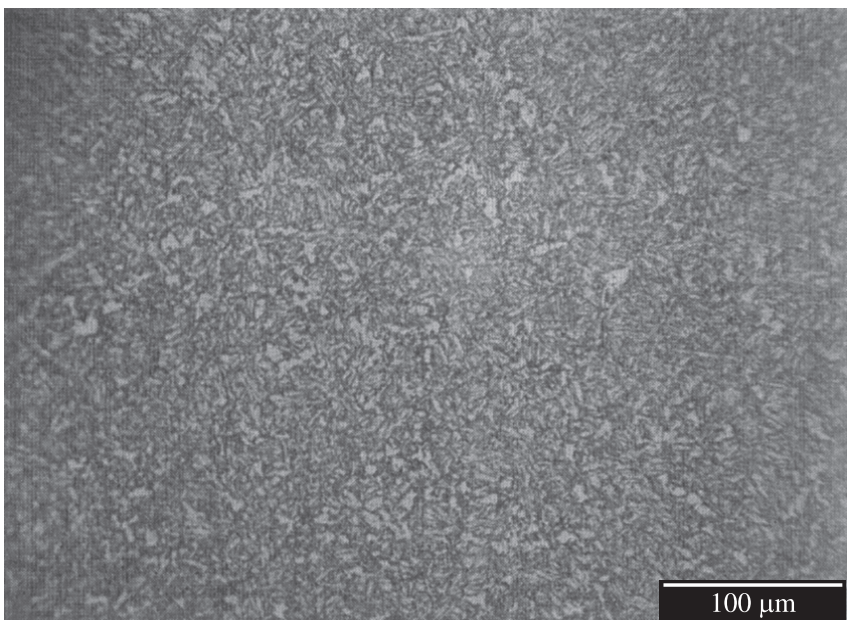

(c)

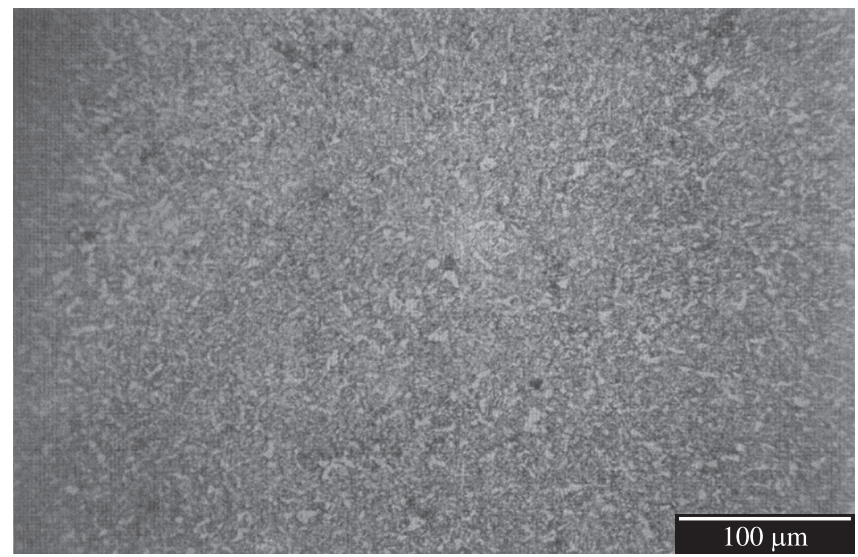

(b)

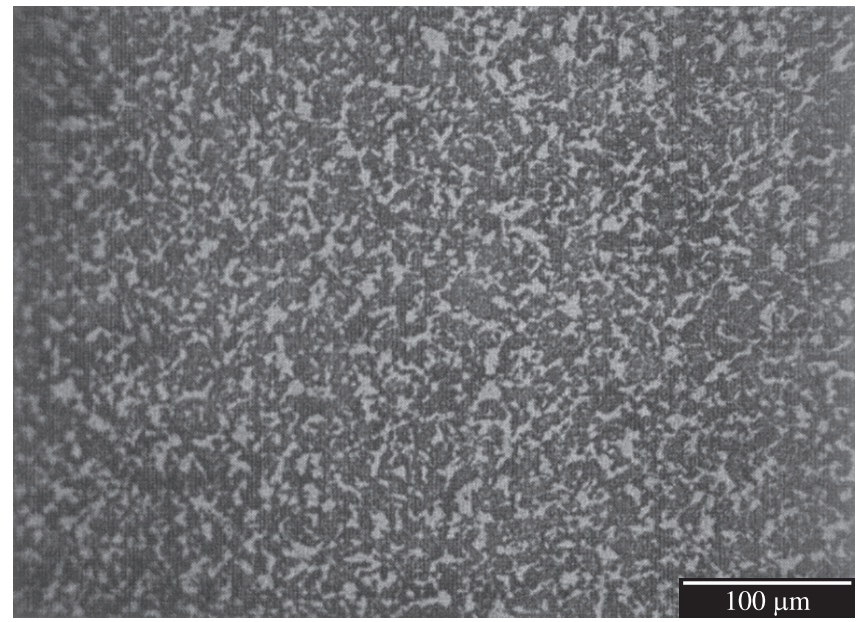

(d)

Figure 13. a-d) Revealed the microstructures of the phases that are present. a) Microstructure of as-rolled 5SP steel etched in 2\% Nital. (Pearlitic-Ferritic Structure). b) Microstructure of heat treated specimen A2 (Q+Q + L + T) etched in 2\% Nital. (Duplex Ferrite - Martensite Microstructure). c) Microstructure of heat treated specimen B2 $(\mathrm{Q}+\mathrm{L}+\mathrm{T})$ etched in 2\% Nital. (Duplex Ferrite - Martensite Microstructure). d) Microstructure of heat treated specimen C2 $(\mathrm{L}+\mathrm{T})$ etched in $2 \%$ Nital.(Duplex Ferrite - Martensite Microstructure).

volume fraction of the second phase was observed to be low but the carbon content enhances the hardness, which in turn produce good tensile strength. This mechanism made the processes to produce low yield-to-tensile strength ratio of 73 to $79 \%$ when compares with that of the as-rolled sample with a ratio of $83 \%$.

\section{Conclusion}

The results from the research have shown that, the mechanical properties of rolled medium carbon steel can be improved by these heat treatment processes. It was noticed that as the heat treatment processes increases from $\mathrm{L}+\mathrm{T}$ to $\mathrm{Q}+\mathrm{Q}+\mathrm{L}+\mathrm{T}$, the improvement in the properties are enhanced. Also, lamellae formation at $745{ }^{\circ} \mathrm{C}$ tends to give best results in all the processes. It was observed that, the steel sample $\mathrm{A}_{2}$ developed by Quenching + Quenching + Lamellae Formation + Tempering $(\mathrm{Q}+\mathrm{Q}+\mathrm{L}+\mathrm{T})$ processed at a lamellae formation temperature of $745{ }^{\circ} \mathrm{C}$ has the best ultimate tensile strength of $618 \mathrm{~N} . \mathrm{mm}^{-2}$, yield ratio of $79 \%$, hardness value of $61.50 \mathrm{HRA}$ with excellent combination of impact strength of $57.90 \mathrm{~J}$ which are very attractive for structural applications. This was followed by steel sample B developed by Quenching + Lamellae Formation + Tempering $(\mathrm{Q}+\mathrm{L}+\mathrm{T})$ processed at a lamellae formation temperature of $745^{\circ} \mathrm{C}$ with ultimate tensile strength of 614 N.mm ${ }^{-2}$, yield ratio of $79 \%$, hardness value of 59.70 HRA with excellent combination of impact strength of $58.60 \mathrm{~J}$ which are also very attractive for structural applications.

Also, the results revealed that, the corrosion resistance of the rolled medium carbon steel can be improved by carrying out heat treatment on the steel. This is because better corrosion properties than the as-rolled medium carbon steel was obtained from the heat treated steel samples. The steel developed by Quenching + Lamellae Formation + Tempering $(\mathrm{Q}+\mathrm{L}+\mathrm{T})$ process has the best corrosion properties followed by Lamellae Formation + Tempering $(\mathrm{L}+\mathrm{T})$ process and Quenching + Quenching + Lamellae Formation + Tempering $(\mathrm{Q}+\mathrm{Q}+\mathrm{L}+\mathrm{T})$ process at a lamellae formation temperature of $745{ }^{\circ} \mathrm{C}$ respectively.

\section{References}

1. Smith WF and Hashemi J. Foundations of Materials Science and Engineering. 4th ed. Boston: McGraw - Hill Book; 2006. p. 28-36.

2. Ashby MF and Jones DRH. Engineering Material 2: An Introduction to Microstructure, Processing and Design. London: Elsevier Science Ltd; 1994. $352 \mathrm{p}$.

3. Oladele IO and Adewuyi BO. Corrosion Behaviour of Dual-Phase Steel in $\mathrm{NaCl}, \mathrm{Na}_{2} \mathrm{SO}_{3}$ and Seawater Environments. Journal of Engineering and Earth Sciences. 2007; 2(1):30-34. 
4. Callister Junior WD. Material Science and Engineering: An introduction. New York: John Willey \& Sons, Inc; 1997. 290 p.

5. Chen HC and Cheng G-H. Effect of Martensite Strength on the Tensile Strength of dual phase Steel. Journal of Materials Science. 1989; 24:1991-1994. http://dx.doi.org/10.1007/BF02385411

6. Davies RG. Deformation behavior of a vanadium-strengthened dual phase steel. Metallurgical Transactions A: Physical Metallurgy and Materials Science. 1978; 9A(1):41-52. http://dx.doi.org/10.1007/BF02647169

7. Speich GR, Demarest SA and Miller RL. Formation of austenite during intercritical annealing of dual-phase steels. Metallurgical Transactions A: Physical Metallurgy and Materials Science. 1981;12A:1419-28. http:// dx.doi.org/10.1007/BF02643686

8. Kim NJ and Thomas G. Effects of morphology on the mechanical behavior of a dual phase Fe/2Si/0.1C steel. Metallurgical Transactions A: Physical Metallurgy and Materials Science. 1981;12A(3):483-9. http://dx.doi. org/10.1007/BF02648546

9. Liedl U, Traint S and Werner EA. An unexpected feature of the stressstrain diagram of dual-phase steel. Computational Materials Science. 2002; 25:122-8. http://dx.doi.org/10.1016/S0927-0256(02)00256-2

10. Speich GR and Miller RL. Mechanical properties of ferrite-martensite steel. In: Kot RA and Morris JW, editors. Structure and properties of dual-phase steels. New York: TMS-AIME; 1979.
11. Rashid MS. Relationship between steel microstructure and formability, formable HSLA and dual-phase steel. In: Davenport AT, editor. Formable HSLA and dual phase steels. New York: TMS-AIME; 1979. p. 1-24.

12. Bayram A, Uguz A and Ula A. Effects of microstructure and notches on the mechanical properties of dual-phase steels. Materials Characterization. 1999;43(4):259-69. http://dx.doi.org/10.1016/S1044-5803(99)00044-3

13. Mondal DK and Dey RM. Effect of grain size on the microstructure and mechanical properties of a C-Mn-V dual-phase steel. Materials Science \& Engineering A Structural Materials : Properties, Microstructure and Processing. 1992;A149(2):173-81.

14. Gorni AA. Steel Forming and Heat-Treating Hand Book. Sao Vicente, Brazil; 2004. vol. 2, 4 p.

15. Mamora O. Yukito, T; Hitoshi, K. and Yuji, F.. Development of New Steel Plates for structural use, Nippon Steel Technical Report, No 44; 1990. p. 8-15.

16. Adewuyi BO, Afonja AA and Adegoke CO. Effects of Isothermal Transformation on the Fatigue strength of Austempered Ductile Iron, Botswana Journal of Technology, vol. 14, No 2; 2005. p. 22.

17. Callister Junior WO. Material Science and Engineering: An introduction. John Willey\& Sons, Inc; 1999. p. 322-328.

18. Faleke EO. Metallurgical Investigation of a Corroded Peugeot Car Body. [Thesis] Akure: Federal University of Technology; 1987. 